\title{
SYNTHESIS AND TESTING CATALYSTS BASED ON FLY ASH FROM THERMAL POWER PLANTS AND NATURAL ZEOLITE FOR GAS EMISSIONS PURIFICATION AND CATALYTIC PROCESSING OF HEAVY OIL
}

\author{
T.V. Shakiyeva ${ }^{1}$, L. R. Sassykova ${ }^{1,}$, A.A. Khamlenko ${ }^{1}$, A.R. Sassykova ${ }^{2}$, \\ A.A. Batyrbayeva ${ }^{1}$, Zh. M. Zhaxibayeva ${ }^{3}$, M. A. Kozhaisakova ${ }^{4}$, \\ A. Muratova ${ }^{1}$, B.T. Dossumova ${ }^{1}$, T. S. Abildin ${ }^{1}$ and M. Zhumagali ${ }^{1}$ \\ ${ }^{1}$ Al-Farabi Kazakh National University, Almaty-050040, Kazakhstan \\ ${ }^{2}$ Almaty College of Economics and Law, Almaty-050004, Kazakhstan \\ ${ }^{3}$ Abai Kazakh National Pedagogical University, Almaty-050000, Kazakhstan \\ ${ }^{4}$ Almaty Technological University, Almaty, Kazakhstan \\ ${ }^{\circledR}$ Corresponding Author: larissa.rav@mail.ru
}

\begin{abstract}
In this study, hollow microspheres based on fly ash from the Ekibastuz coal field (Kazakhstan) and natural zeolite from the Taizhuzgen field (Kazakhstan) were used for the synthesis of catalysts. The catalysts were tested in the process of sulfur dioxide oxidation with different $\mathrm{SO}_{2}$ content in the $\mathrm{SO}_{2}$-Ar gas mixture at a flow vortex plant of the "Emulsifier" type with a capacity of $2 \mathrm{~m}^{3} / \mathrm{h}$. Technology for the oxidation of $\mathrm{SO}_{2}$ with oxygen in an aqueous solution has been developed and the best technological parameters for the selective oxidation of $\mathrm{SO}_{2}$ with the production of sulfuric acid as a product have been determined. The degree of $\mathrm{SO}_{2}$ sorption is reached up to $95 \%$. Also, the prepared catalysts were tested in the process of redox-catalytic cracking of fuel oil (with preliminary electromagnetic excitation of hydrocarbon molecules) to obtain light carbon fractions. The fuel oil of the Amangeldy Gas Processing Plant (AGPP, Kazakhstan) of the M-100 brand was studied as a feedstock. On the optimal catalyst in the products of oxidative cracking of fuel oil, the fraction of light gas oil makes up the main part. The resulting light gas oil contains a significant amount of alpha-olefins, which are scarce raw materials for the production of synthetic additives and oils.

Keywords: Fly Ash, Natural Zeolite, Water and Gas Purification, Highly Toxic Organic Compounds, Catalytic Cracking, Fuel Oil.
\end{abstract}

RASĀYAN J. Chem., Vol. 14, No.4, 2021

\section{INTRODUCTION}

The problem of the utilization of ash and slag of the Thermal Power Plants (TPP) or CHP working on solid fuel is very urgent. Fly ash contains several components with valuable and unique technological properties: aluminosilicate hollow microspheres (AHM, which are the most original and perhaps the most valuable components of ash), magnetite microbeads, the unburnt carbonic particles, ferrosilicon and carbonate microspheres. ${ }^{1-5}$ The value of AHM is determined by the fact that they can be ideal fillers. The main components of ash and slag are $\mathrm{SiO}_{2}$ (up to $60 \%$ ) and $\mathrm{Al}_{2} \mathrm{O}_{3}$ (up to $25 \%$ ). The content of $\mathrm{Fe}_{2} \mathrm{O}_{3}$ is up to $15 \%$, of $\mathrm{CaO}$ from 1.5 to $4.5 \%$, of $\mathrm{K}_{2} \mathrm{O}$ from 2.0 to $4.5 \%$. AHM is in great demand in many countries and ash dumps are technogenic deposits of valuable products. ${ }^{2,3,6,7}$ Features of the chemical and mineralphase composition of cenospheres make it possible to synthesize microspheric fuel cracking catalysts based on them.

Thermal power plants, oil and gas processing plants are among the most important sources of atmospheric pollution: the atmosphere is polluted by emissions of sulfur and nitrogen oxides, carbon monoxide and its accompanying benzapyrene, and other harmful compounds, most of the emissions are toxic. ${ }^{8-12}$ Gas treatment plants of CHP, as well as methods associated with structural changes of the unit, as a rule, are very expensive and not always economically justified. Therefore, it is very important to develop low-cost Rasayan J. Chem., 14(4), 2216-2223(2021)

http://doi.org/10.31788/RJC.2021.1446511

This work is licensed under a CC BY 4.0 license. 
RASĀYAN J. Chem.

Vol. 14 | No. 4 |2216-2223| October- December | 2021

methods for reducing emissions of pollutants using sorbents and catalysts based on local raw materials. ${ }^{11,12}$

Traditional processes of catalytic cracking of heavy petroleum raw materials require continuous regeneration of expensive zeolite-containing catalysts and sophisticated equipment. ${ }^{13-15}$ Development of methods for the activation of heavy oil raw materials by such physical influences as ultrasound, magnetic treatment, microwave, infrared radiation, mechanochemistry, ultraviolet radiation can be an alternative or addition to traditional oil refining processes. One of the most promising methods for producing light hydrocarbon fractions is the implementation of catalytic cracking of heavy oil raw materials in the presence of air additives in the reaction medium, i. e. in an oxidizing medium. ${ }^{16-23}$

In this work, the hollow microspheres based on fly ash from the Ekibastuz coal deposit (Kazakhstan), produced as a result of the operation of TPP-2 in Almaty (Kazakhstan) and natural Kazakhstan zeolite from Taizhuzgen field were selected and used for the preparation of catalysts. The research was carried out on the development of an effective way of purification of gas emissions from sulfur dioxide and also for oxidative catalytic cracking of fuel oil (with preliminary electromagnetic excitation of hydrocarbon molecules) to obtain light carbon fractions.

\section{EXPERIMENTAL}

\section{Material and Methods}

For this investigation, the catalysts were synthesized based on Kazakhstan's natural zeolite of the Taizhuzgen deposit and fractions of cenospheres resulting from the combustion of coal of Ekibastuz field (Kazakhstan) at the Almaty TPP-2 (Kazakhstan) with an aluminosilicate module $\mathrm{SiO}_{2} / \mathrm{Al}_{2} \mathrm{O}_{3}=3.2$ and iron content of 3.03-3.67 wt. \% in $\mathrm{Fe}_{2} \mathrm{O}_{3}$. Coals of Ekibastuz coal basin (Kazakhstan) of medium metamorphism $\left(\mathrm{R}^{\circ} 0.8-1.3 \%\right)$, grade $\mathrm{CC}$, high ash, very difficult to enrich, $\mathrm{W}^{\mathrm{r}} 6.5 \%, \mathrm{~V}^{\text {daf }} 24-32, \mathrm{St}^{\mathrm{d}} 0.5-$ $0.8 \%$, Qs ${ }^{\mathrm{daf}} 33 \mathrm{MJ} / \mathrm{kg}, \mathrm{Qi}^{\mathrm{r}} 14-19 \mathrm{MJ} / \mathrm{kg} .{ }^{8-10,24,25}$ Ekibastuz coal is used in the hydroelectric power station of the Urals (Russia) and Kazakhstan. The scheme for producing mycospheres from the Ekibastuz coal ash is based on the use of dry magnetic separation methods, particle size classification and gravity separation using liquid separating media.

\section{General Procedure}

The kinetics of sodium sulfite oxidation by oxygen was studied under stationary conditions in a glass gradientless thermostated "duck"-type reactor, with a potentiometric device. The kinetic regime was ensured by intensive shaking of the reactor (300-400 oscillations per minute), the volume of the liquid phase was no more than $40 \mathrm{~cm}^{3}$, with a total volume of the reactor of $180 \mathrm{~cm}^{3}$. The reaction rate was determined by oxygen uptake. The process was carried out according to the previously developed methodology. ${ }^{3,5,15,18}$ The efficiency of the process was defined by the results of X-ray phase analysis and by visual control of the quality of the selected products using a microscope. A vibration magnetometer AMH-500 Hysteresisograph (Italy) was used for magnetic measurements.

It is known that the most suitable device that provides the intensity of gas-liquid mass exchange can be a device that performs gas-liquid mixing in a turbulent mode. Examples of such reactors are vortex apparatuses such as emulsifiers and Venturi tubes. The main element of the vortex apparatus of the emulsifier is a swirler, the gas passes at high speed through the slits between the guide vanes, acquires a rotational motion, splits the liquid entering the contact zone into small droplets at the exit of the slits, and engages them in a joint rotational-translational motion. Under the action of the centrifugal force that occurs during the rotation of the two-phase flow, liquid droplets move to the periphery and settle on the wall of the device, forming a rotating liquid ring.

In this research catalysts based on cenospheres and natural zeolite were tested in the process of sulfur dioxide oxidation at a pilot plant with different $\mathrm{SO}_{2}$ content in the $\mathrm{SO}_{2}$-Ar gas mixture. A flow vortex installation of the "Emulsifier" type, with a capacity of $2 \mathrm{~m}^{3} / \mathrm{h}$ was used. This installation provided an intensive gas-liquid mass exchange and allowed to remove the diffusion inhibition as a result of the dissolution of sulfur dioxide. The studies were carried out according to the following method: a certain volume of the catalytic solution was placed in the emulsifier and a gas mixture of $\mathrm{SO}_{2}-\mathrm{Ag}$ and air was passed through it simultaneously at a speed of $1 \mathrm{~m}^{3} / \mathrm{h}$ and a speed of $1 \mathrm{~m}^{3} / \mathrm{h}$. Sulfur dioxide at the reactor inlet and after purification was quantified by iodometry and using hydrogen peroxide. 
RASĀYAN J. Chem.

Vol. 14 | No. 4 |2216-2223| October- December | 2021

Also the catalytic cracking of M-100 grade fuel oil from Amangeldy Gas Processing Plant (AGPP, Kazakhstan) was studied. Distillations at atmospheric and reduced pressures were used to establish the fractional composition of fuel oil. The following operations are performed for starting and stationary operation of the fuel oil oxidative catalytic cracking reactor: purging of the reactor with an inert gas $\left(\mathrm{CO}_{2}\right.$ after the combustion furnace of gaseous products or nitrogen); heating of the reactor to a temperature of $470{ }^{\circ} \mathrm{C}$ using an induction unit; stopping purging and blocking the supply of inert gas to the reactor; continuous supply to the central zone of the flow reactor through the inlet pipe of $0.2 \%$ catalyst suspension in fuel oil with a volume rate of $1.0 \mathrm{~h}^{-1}$. The volume velocity is defined as the ratio of the volume of suspension introduced into the reactor within 1 hour to the volume of the entire reactor. Then are performed: a continuous supply of air to the central zone of the flow reactor through the inlet pipe with a volumetric speed of $0.15 \mathrm{~h}^{-1}$ simultaneously with the supply of a mixture of catalyst and fuel oil; continuous discharge from the flow reactor of tar mixed with spent catalyst into the receiving tank; the continuous output of gas. The vapor-like cracking products are directed from the flow reactor to the flow refrigerator-separator. Fractions of gasoline, light gas oil, vacuum gas oil and heavy residue ( $\mathrm{T}_{\text {boiling }}>$ $500^{\circ} \mathrm{C}$ ) were taken. The content of each fraction (wt. \%) was determined by the gravimetric method. The sulfur content of the liquid fuel and vacuum gas oil was determined by high-temperature oxidation of the samples followed by acid-base titration of the resulting sulfur dioxide. In the initial fuel oil, and gasoline and kerosene-gas oil fractions formed during cracking, the presence of oxygen and sulfur-containing compounds were determined by the infrared spectral method.

\section{RESULTS AND DISCUSSION}

NMR-analysis shows, that the proton spectrum of fuel oil from AGPP contains ${ }^{1} \mathrm{H}$ signals of paraffinic, naphthenic and aromatic compounds, which are the main components of the mixture (Fig.-1). Methyl proton signals from saturated hydrocarbons were detected as a broadened singlet at $0.90 \mathrm{ppm}$. A highintensity signal with a chemical shift of $1.28 \mathrm{ppm}$ indicates a significant content of protons of methylene groups of aliphatic cyclic and acyclic hydrocarbons. The highest-frequency signals $(\delta=6.97-7.76 \mathrm{ppm})$ indicate the presence of monoaromatic compounds and condensed aromatic rings in the fuel oil. Signals of methyl protons of saturated hydrocarbons are noted as a broadened singlet at $0.90 \mathrm{ppm}$. A small amount of $\mathrm{CH}_{3}$ groups was noted in the $\alpha$-position to the aromatic ring $(\delta=2.30-2.63 \mathrm{ppm})$. In the range of 2.70-4.50 ppm there is probably the resonance of protons of the $\mathrm{CH}_{2}$ and $\mathrm{CH}$ groups in the $\alpha$-position of aromatic compounds. ${ }^{26-28}$
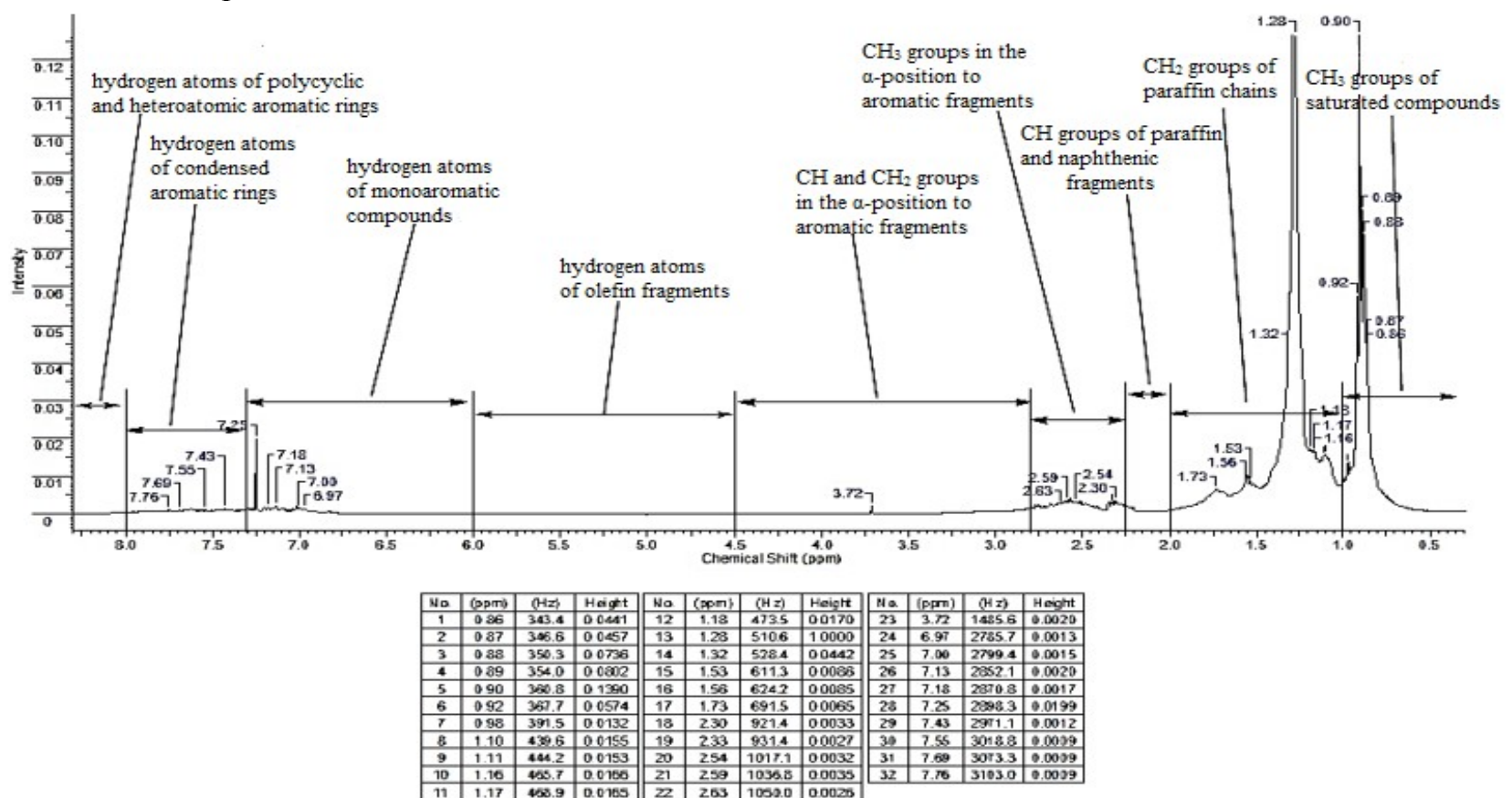

Fig.-1: NMR Spectrum $\left({ }^{1} \mathrm{H}\right.$ spectrum $)$ of Fuel Oil from the AGPP 
According to our research, the optimum sizes of active parts of the catalyst are in the range 45-55 $\mathrm{nm}$. The specific surface of the catalyst found from the full isotherms of low-temperature adsorption of nitrogen by BET method makes $12.55 \mathrm{~m}^{2} / \mathrm{g}$. The integral volume of pores is $0.57 \mathrm{ml} / \mathrm{g}$. Fig. -2 shows SEM images of isolated aluminosilicate microspheres extracted from fly ash of Almaty TPP-2, working on the Ekibastuz coal.
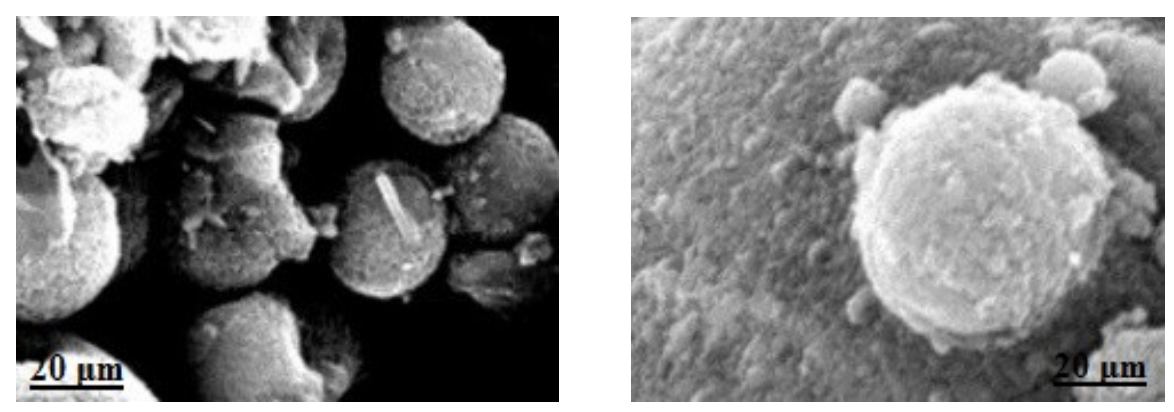

Fig.-2: SEM Images of Aluminosilicate Microspheres extracted from Fly Ash of TPP-2 (Almaty), working on the Ekibastuz Coal

The typical chemical composition of isolated aluminosilicate microspheres is represented by different oxides: oxides of aluminum, silicon, iron, calcium, strontium, zirconium and titanium (wt. \%): $\mathrm{Al}_{2} \mathrm{O}_{3}$ (26.3); $\mathrm{SiO}_{2}$ (59.05); $\mathrm{CaO}$ (1.88); $\mathrm{TiO}_{2}$ (1.16); $\mathrm{Fe}_{2} \mathrm{O}_{3}$ (5.45); $\mathrm{Na}_{2} \mathrm{O}$ (1.82); $\mathrm{S}$ (1.1); P (0.51); $\mathrm{SrO}$ (0.043); $\mathrm{ZrO}(0.051)$. Thus, the composition of cenospheres is very valuable, which makes it possible to obtain catalysts or sorbents that are multifunctional and resistant to poisoning.

According to X-ray diffraction analysis, the Taizhuzgen zeolite contains the following components (concentration, \% intensity): Fe (49.939/739.15); Ca (1.715/9.16); $\mathrm{Sr}$ (0.270/1.98); Mn (0.129/1.81); Al (21.955/0.31); Si (23.114/0.98); Ti (1.903/20.87) and K (0.976/1.96).

\section{Purification of Gas Emissions from Sulphur Dioxide}

The results of testing a modified catalyst based on fly ash on a flow-through vortex installation of the "Emulsifier" type, with a capacity of $2 \mathrm{~m}^{3} / \mathrm{h}$, are presented in Table-1. Tests have shown that the sulfur dioxide removal rate was $86-95 \%$.

Table-1: Catalytic Purification of Gases from $\mathrm{SO}_{2}$. The Ratio of the Aqueous Solution to the Catalyst is $-1: 1$.

\begin{tabular}{c|c|c|c}
\hline \multicolumn{2}{c}{ Solution Composition, mol / } & $\mathrm{SO}_{2}$ Content in the Gas Mixture, $\mathrm{mg} / \mathrm{m}^{3}$ \\
\hline $\mathrm{FeCl}_{3}$ & Fulvic Acid & Before Cleaning & After Cleaning \\
\hline $0.5 \cdot 10^{-3}$ & $2.3 \cdot 10^{-3}$ & 1,511 & 200 \\
\hline $1.0 \cdot 10^{-3}$ & $2.3 \cdot 10^{-3}$ & 104 & 150 \\
\hline $2.0 \cdot 10^{-3}$ & $2.3 \cdot 10^{-3}$ & 1,511 & 120 \\
\hline $1 \cdot 10^{-3}$ & $1.15 \cdot 10^{-3}$ & 1,511 & 205 \\
\hline $1 \cdot 10^{-3}$ & $4.6 \cdot 10^{-3}$ & 1,511 & 170 \\
\hline $1 \cdot 10^{-3}$ & $9.2 \cdot 10^{-3}$ & 1,511 & 130 \\
\hline $1 \cdot 10^{-3}$ & $2.3 \cdot 10^{-3}$ & 1,511 & 180 \\
\hline $1 \cdot 10^{-3}$ & $2.3 \cdot 10^{-3}$ & 1,511 & 120 \\
\hline $1 \cdot 10^{-3}$ & $2.3 \cdot 10^{-3}$ & 1,511 & 90 \\
\hline
\end{tabular}

The effect of the partial pressure of sulfur dioxide on the oxidation of sulfur dioxide with oxygen in an aqueous solution in the range of $\mathrm{P}_{\mathrm{SO} 2}$ from $420 \mathrm{mg} / \mathrm{m}^{3}$ to $1,511 \mathrm{mg} / \mathrm{m}^{3}$ in a gas mixture $\mathrm{SO}_{2}-\mathrm{ArO}_{2}$ was studied at $\mathrm{P}_{\mathrm{O} 2}=21 \mathrm{vol} . \%$. The test results are summarized in Table-2.

In the studied interval of $\mathrm{P}_{\mathrm{SO} 2}$, the degree of conversion at the maximum load of the pilot plant was from 60 to $86 \%$, increasing with an increase in the partial pressure of sulfur dioxide in the gas mixture. After the absorption of $4.7 \mathrm{~m}^{3}$ of gaseous sulfur dioxide (the concentration of $\mathrm{SO}_{2}$ in the aqueous solution is 0.4 mol / L), the aqueous solution was separated from the catalyst and analyzed. Analysis showed the 
RASĀYAN J. Chem.

Vol. 14 | No. 4 |2216-2223| October- December | 2021

presence of about $70 \% \mathrm{H}_{2} \mathrm{SO}_{4}$ in the solution. Then a new portion of water is poured in and the gas purification from $\mathrm{SO}_{2}$ is continued. The activity of the catalyst did not change after that. Thus, the use of the catalysts developed by us based on the fly ash cenospheres of CHPs for the purification of gases from sulfur dioxide with its simultaneous oxidation to sulfur trioxide makes it possible to significantly simplify the technological scheme of gas purification with the simultaneous production of sulfuric acid.

Table-2: Catalytic Oxidation of Sulfur Dioxide with Oxygen at Different Partial Pressures of Sulfur Dioxide. Conditions: $\mathrm{T}=30^{\circ} \mathrm{C},=5 \cdot 10^{-3} \mathrm{~mol} / \mathrm{L}$, Ash Sample $-0.1 \mathrm{~g}$. Gas Mixture Feed Rate is $2 \mathrm{~m}^{3} / \mathrm{h}$.

\begin{tabular}{c|c|c|c}
\hline \multirow{2}{*}{$\begin{array}{c}\mathrm{P}_{\mathrm{SO} 2} \text { in the Gas Mixture, } \\
\text { Vol.\% }\end{array}$} & \multicolumn{2}{|c|}{$\mathrm{SO}_{2}$ Content in the Gas Mixture, $\mathrm{mg} / \mathrm{m}^{3}$} & \multirow{2}{*}{ Degree of $\mathrm{SO}_{2}$ Conversion, $\%$} \\
\cline { 2 - 3 } & Before Cleaning & After Cleaning & 86 \\
\hline 1.21 & 1,511 & 200 & 85 \\
\hline 1.03 & 1,286 & 186 & 82 \\
\hline 0.85 & 1,061 & 181 & 77 \\
\hline 0.65 & 811 & 180 & 66 \\
\hline 0.42 & 524 & 175 & 60 \\
\hline 0.34 & 424 & 168 & \\
\hline
\end{tabular}

\section{Catalytic Cracking of Fuel Oil of the M-100 Brand from AGPP}

The previous analysis shows that fuel oil of M-100 brand used for cracking is low-sulfur (Table-3). ${ }^{5,15}$

Table-3. Fractional Composition and Sulfur Content in Fuel Oil from AGPP, Grade M-100

\begin{tabular}{c|l|c|c}
\hline \multirow{2}{*}{ No } & \multirow{2}{*}{ Fractional Composition } & \multicolumn{2}{|c}{ Content, wt. \% } \\
\cline { 3 - 4 } & & Hydrocarbon Fractions & Sulfur \\
\hline 1 & initial fuel oil & 100.0 & 0.7 \\
\hline 2 & gasoline & 0.3 & - \\
\hline 3 & light gas oil & 41.1 & 0.4 \\
\hline 4 & vacuum gas oil & 18.4 & 1.3 \\
\hline 5 & heavy residue & 39.3 & 0.7 \\
\hline 6 & losses & 0.9 & - \\
\hline
\end{tabular}

According to the IR spectral analysis of the fractions of the initial fuel oil, gasoline, light gas oil and heavy residue after the conversion of fuel oil from AGPP, their composition, together with alkanes of normal structure, includes a significant amount of olefin and aromatic hydrocarbons.

The presence of olefins is indicated by strong absorption bands at 3,080-3,050 $\mathrm{cm}^{-1}$ in the spectra of gasoline and two fractions of light gas oil, as well as a band of medium intensity for a heavy residue. Aromatic hydrocarbons are also concentrated in light fractions, since the intensity of the absorption bands at 1,$700 ; 1,640$ and $1,600-1,580 \mathrm{~cm}^{-1}$ decreases during the transition from gasoline to light gas oil (185$340^{\circ} \mathrm{C}$ ), and in the spectra for the $340-350^{\circ} \mathrm{C}$ fraction and the heavy residue of the absorption bands at 3,$150 ; 1,700$ and $1,620 \mathrm{~cm}^{-1}$ are absent. However, the bulk of all fractions is composed of aliphatic hydrocarbons with absorption bands characteristic of deformation vibrations of these molecules at 1,480$1,380 \mathrm{~cm}^{-1}$ and $980-700 \mathrm{~cm}^{-1} \cdot 29-31$

Results of the X-ray phase analysis of the catalysts based on fly ash from TPP with the addition of the activated Taizhuzgen zeolite are presented in Table-4.

Table-4: X-ray Phase Analysis of Catalysts for Oxidative Cracking Fuel Oil (the numbering of minerals is given in decreasing order of their concentration in the analyzed samples)

\begin{tabular}{l|c|c|c|c}
\hline \multicolumn{1}{c}{ Mineral Composition } & \multicolumn{2}{c|}{ Un-activated } & \multicolumn{2}{c}{ Optimal } \\
\cline { 2 - 5 } & $\begin{array}{c}\text { Before } \\
\text { Calcination }\end{array}$ & $\begin{array}{c}\text { After } \\
\text { Calcination }\end{array}$ & $\begin{array}{c}\text { Before } \\
\text { Calcination }\end{array}$ & $\begin{array}{c}\text { After } \\
\text { Calcination }\end{array}$ \\
\hline Chamosite $2\left[\left(\mathrm{Fe}^{2+}, \mathrm{Mg}, \mathrm{Fe}^{3+}\right)_{5} \cdot \mathrm{Al}\left(\mathrm{Si}_{3} \mathrm{AlO}_{10}\right) \cdot(\mathrm{OH})_{8}\right]$ & 1 & 1 & 1 & 1 \\
\hline Hematite $\mathrm{Fe}_{2} \mathrm{O}_{3}$ & 2 & 2 & 2 & 2 \\
\hline Diaspore $($ boehmite $) \mathrm{AlO}(\mathrm{OH})$ & 3 & 4 & 3 & 5 \\
\hline Corundum $\mathrm{Al}_{2} \mathrm{O}_{3}$ & 4 & 3 & 4 & 3 \\
\hline The cell parameters of chamosite zeolite structure & absent & absent & absent & $\begin{array}{c}\mathrm{A}_{0}=12.8 \AA \mathrm{B}_{0}=6.5 \AA \\
\mathrm{C}_{0}=3.1 \AA \beta=127.2\end{array}$ \\
\hline
\end{tabular}


RASĀYAN J. Chem.

Vol. 14 | No. 4 |2216-2223| October- December | 2021

On the optimal catalyst in the products of oxidative cracking of fuel oil, the fraction of light gas oil is the main part. Therefore, to elucidate the reaction mechanism, we set the task to determine the individual composition of the hydrocarbons included in this fraction. The results of gas chromatography-mass spectrometric analysis are presented in Table-5.

Table-5. Individual Hydrocarbon Composition of Light Gas Oil obtained as a Result of Oxidative Cracking of Fuel Oil M-100 from AGPP.

Cracking conditions: Catalyst based on fly ash from TPP-2 with the addition of Taizhuzgen zeolite activated by ion exchange (simultaneously with $\mathrm{La}^{3+}$ and $\mathrm{NH}_{4}{ }^{+}$ions); $\omega_{\text {suspension }}=1.0 \mathrm{~h}^{-1}, \omega_{\text {air }}=0.15 \mathrm{~h}^{-1}, 0.2 \mathrm{wt} . \%$ in starting material, $\mathrm{T}=470^{\circ} \mathrm{C}$.

\begin{tabular}{|c|c|c|c|c|c|}
\hline No & Hydrocarbons & $\begin{array}{c}\text { Content, } \\
\%\end{array}$ & No & Hydrocarbons & $\begin{array}{c}\text { Content, } \\
\%\end{array}$ \\
\hline 1 & heptene- $1, \mathrm{C}_{7} \mathrm{H}_{14}$ & 1.92 & 25 & hexadecane, $\mathrm{C}_{16} \mathrm{H}_{34}$ & 3.29 \\
\hline 2 & heptane, $\mathrm{C}_{7} \mathrm{H}_{16}$ & 2.82 & 26 & 2-methylhexadecane, $\mathrm{C}_{17} \mathrm{H}_{36}$ & 0.72 \\
\hline 3 & octene- $1, \mathrm{C}_{8} \mathrm{H}_{16}$ & 0.69 & 27 & 5-heptadecene, $\mathrm{C}_{17} \mathrm{H}_{34}$ & 0.77 \\
\hline 4 & octane, $\mathrm{C}_{8} \mathrm{H}_{18}$ & 1.30 & 28 & heptadecane, $\mathrm{C}_{17} \mathrm{H}_{36}$ & 3.47 \\
\hline 5 & nonene- $1, \mathrm{C}_{9} \mathrm{H}_{18}$ & 0.67 & 29 & 2,6,10,14-tetramethyltetradecane, $\mathrm{C}_{18} \mathrm{H}_{38}$ & 1.43 \\
\hline 6 & nonan, $\mathrm{C}_{9} \mathrm{H}_{20}$ & 1.07 & 30 & 2,6,11-trimethylpentadecane, $\mathrm{C}_{18} \mathrm{H}_{38}$ & 0.70 \\
\hline 7 & decene- $1, \mathrm{C}_{10} \mathrm{H}_{20}$ & 0.83 & 31 & 2,6,10-trimethylpentadecane, $\mathrm{C}_{18} \mathrm{H}_{38}$ & 0.53 \\
\hline 8 & decane, $\mathrm{C}_{10} \mathrm{H}_{22}$ & 1.37 & 32 & 1-octadecene, $\mathrm{C}_{18} \mathrm{H}_{36}$ & 1.02 \\
\hline 9 & undecene, $\mathrm{C}_{11} \mathrm{H}_{22}$ & 1.01 & 33 & octadecane, $\mathrm{C}_{18} \mathrm{H}_{38}$ & 3.96 \\
\hline 10 & undecane, $\mathrm{C}_{11} \mathrm{H}_{24}$ & 1.43 & 34 & 2- methyloctadecane, $\mathrm{C}_{19} \mathrm{H}_{40}$ & 2.42 \\
\hline 11 & pentylcyclohexane, $\mathrm{C}_{11} \mathrm{H}_{22}$ & 0.77 & 35 & 2,4- dimethylheptadecane, $\mathrm{C}_{19} \mathrm{H}_{40}$ & 1.60 \\
\hline 12 & dodecene- $1, \mathrm{C}_{12} \mathrm{H}_{24}$ & 1.26 & 36 & nonadecane, $\mathrm{C}_{19} \mathrm{H}_{40}$ & 4.88 \\
\hline 13 & dodecane, $\mathrm{C}_{12} \mathrm{H}_{26}$ & 2.24 & 37 & 6- propylheptadecane, $\mathrm{C}_{20} \mathrm{H}_{42}$ & 1.82 \\
\hline 14 & 1-butyl-2-pentylcyclopropane, $\mathrm{C}_{12} \mathrm{H}_{24}$ & 0.65 & 38 & 2-methylnoneadecane, $\mathrm{C}_{20} \mathrm{H}_{42}$ & 1.15 \\
\hline 15 & 2,6-dimethylundecane, $\mathrm{C}_{13} \mathrm{H}_{28}$ & 0.70 & 39 & 3-methylnoneadecane, $\mathrm{C}_{20} \mathrm{H}_{42}$ & 0.93 \\
\hline 16 & tridecene- $1, \mathrm{C}_{13} \mathrm{H}_{26}$ & 1.25 & 40 & eicosan, $\mathrm{C}_{20} \mathrm{H}_{42}$ & 6.55 \\
\hline 17 & tridecane, $\mathrm{C}_{13} \mathrm{H}_{28}$ & 2.70 & 41 & 3-methyleicosane, $\mathrm{C}_{21} \mathrm{H}_{44}$ & 1.76 \\
\hline 18 & 3-tetradecene, $\mathrm{C}_{14} \mathrm{H}_{28}$ & 1.31 & 42 & heneicosane, $\mathrm{C}_{21} \mathrm{H}_{44}$ & 6.63 \\
\hline 19 & tetradecane, $\mathrm{C}_{14} \mathrm{H}_{30}$ & 2.88 & 43 & 5- propylnonadecane, $\mathrm{C}_{22} \mathrm{H}_{46}$ & 2.82 \\
\hline 20 & 3-methyltetradecane, $\mathrm{C}_{15} \mathrm{H}_{32}$ & 0.63 & 44 & docosane, $\mathrm{C}_{22} \mathrm{H}_{46}$ & 5.05 \\
\hline 21 & 2,6,1-trimethyldodecane, $\mathrm{C}_{15} \mathrm{H}_{32}$ & 0.51 & 45 & 3-butylnonadecane, $\mathrm{C}_{23} \mathrm{H}_{48}$ & 1.96 \\
\hline 22 & 1- pentadecene, $\mathrm{C}_{15} \mathrm{H}_{30}$ & 1.09 & 46 & tetracosan, $\mathrm{C}_{24} \mathrm{H}_{50}$ & 3.13 \\
\hline 23 & pentadecan, $\mathrm{C}_{15} \mathrm{H}_{32}$ & 3.36 & 47 & pentacosane, $\mathrm{C}_{25} \mathrm{H}_{52}$ & 2.49 \\
\hline 24 & 1-hexadecene, $\mathrm{C}_{16} \mathrm{H}_{32}$ & 0.99 & 48 & heptacosane, $\mathrm{C}_{27} \mathrm{H}_{56}$ & 1.17 \\
\hline
\end{tabular}

As can be seen from Table-5, the formation of $\mathrm{C}_{7}-\mathrm{C}_{12}$ hydrocarbons occurs exclusively due to the symmetric decomposition of $\mathrm{C}_{14}-\mathrm{C}_{24}$ paraffin, since the products of this reaction are the corresponding $\alpha$ olefins and n-alkanes. Thus, as a result of cracking reactions of the M-100 fuel oil from AGPP, the resulting light gas oil contains a significant amount of $\alpha$ - olefins (Table-5), which are a scarce raw material for the production of synthetic additives and oils. It is known from the literature that the best synthetic oils that ensure the operation of equipment in cold climatic conditions are obtained based on oligomers $\alpha$ - olefins $\mathrm{C}_{8}-\mathrm{C}_{12} .{ }^{31-34}$

\section{CONCLUSION}

In this work catalysts based on the hollow microspheres based on fly ash from the Ekibastuz coal deposit (Kazakhstan), obtained as a result of the operation of TPP-2 in Almaty were synthesized and tested in the process of purification of waste gases from sulfur dioxide. The degree of sorption of $\mathrm{SO}_{2}$ is reached up to $95 \%$. It was found that after the accumulation of the product in the solution - sulfuric acid at a concentration of $70 \%$, it can be separated from the catalyst, add a fresh portion of water and continue gas purification. The activity of the catalyst did not change after that. The catalytic systems prepared from fly ash from TPP mixed with natural zeolite were used for oxidative catalytic cracking of fuel oil to obtain light carbon fractions. It was shown that microspheres of fly ash are highly effective sorbents of $\mathrm{SO}_{2}$ and low-temperature catalysts of oxidation of $\mathrm{Na}_{2} \mathrm{SO}_{3}$ with oxygen in water solutions. As a result of the M100 fuel oil cracking reactions, the final light gas oil contains a significant amount of $\alpha$-olefins. 
RASĀYAN J. Chem.

Vol. 14 | No. 4 |2216-2223| October- December | 2021

\section{ACKNOWLEDGEMENT}

We would like to express sincere gratitude for grant financing by the program: "No. AP09260687

Technology for the recovery and disposal of toxic compounds from industrial wastewater".

\section{REFERENCES}

1. T. Sasi, M. Mighani, E. Örs, R. Tawani and M. Gräbner, Fuel Processing Technology, 176, 64(2018), http://doi.org/10.1016/j.fuproc.2018.03.018

2. B. Rubio and M.T. Izquierdo, Waste Management, 30(7), 1341(2010), http://doi.org/10.1016/j.wasman.2010.01.035

3. R. Ibrasheva, V. Yemelyanova, L. Sassykova, B. Dossumova, T. Shakiyeva, E. Shakiyev and B. Baizhomartov, Journal of Chemical Technology and Metallurgy, 56(1), 104(2021)

4. M. Basu, M.Pande, P.B.S. Bhadoria and S.C.Mahapatra, Progress in Natural Science, 19(10), 1173(2009), http://doi.org/10.1016/j.pnsc.2008.12.006

5. V. S. Yemelyanova, B. T. Dossumova, T. V. Shakiyeva, L.R. Sassykova and S. Sendilvelan, International Journal of Mechanical and Production Engineering Research and Development, 9(4), 1079(2019), http://doi.org/10.24247/ijmperdaug2019111

6. W. Wang, Q. Li and J. Zhai, Surface and Interface Analysis, 45(3), 756(2013), http://doi.org/10.1002/sia.5156

7. D.Q.Sang and N.T.Anh, Vietnam Journal of Chemistry, 58(3), 380(2020), http://doi.org/10.1002/vjch.202000003

8. M. Tulepov, Z. Mansurov, L. Sassykova, D. Baiseitov, O. Dalelhanuly, Zh. Ualiev, Sh. Gabdrashova and Zh. Kudyarova, Journal of Chemical Technology and Metallurgy, 54(3), 531(2019)

9. A. Shokanov, M. Vereshchak and I. Manakova, Metals, 10(7), 929(2020), http://doi.org/10.3390/met10070929

10. http://www.mining-enc.ru/e1/ekibastuzskij-ugolnyj-bassejn/

11. M. Prabhahar, S. Sendilvelan and L.R. Sassykova, Indian Journal of Environmental Protection, 38(4), 269(2018)

12. Y.A. Aubakirov, L.R. Sassykova, A.M. Nalibayeva, K. Dossumov, Zh.Kh. Tashmukhambetova, A.S. Zhumakanova, A.K. Zhussupova and N.K. Zhakirova, Oriental Journal of Chemistry, 33(6), 3130(2017), http://doi.org/10.13005/ojc/330655

13. X. Liu, W.Li, H. Zhu, Q. Ge, Y. Chen and H. Xu, Catalysis Letters, 94(1/2), 31(2004), http://doi.org/10.1023/b:catl.0000019327.86674.98

14. Y. Yoshimura, N. Kijima, T. Hayakawa, K. Murata, K. Suzuki, F. Mizukami, K. Matano, T. Konishi, T. Oikawa, M. Saito, T. Shiojima, K. Shiozawa, K. Wakui, G. Sawada, K. Sato, S. Matsuo and N. Yamaoka, Catalysis Surveys from Japan, 4(2), 157(2001), http://doi.org/10.1023/a:1011463606189

15. R. Kh. Ibrasheva, V.S. Yemelyanova, L.R. Sassykova, U. N. Dzhatkambayeva, T.V. Shakiyeva, B.T. Dossumova, N.K. Zhakirova, S. Sendilvelan and T. M. Seilkhanov, Rasayan Journal of Chemistry, 13(4), 2370(2020), http://doi.org/10.31788/RJC.2020.1345948

16. Y. Tanimoto, H. Tanaka, Y. Fujiwara and M. Fujiwara, The Journal of Physical Chemistry A, 102(28), 5611(1998), http://doi.org/10.1021/jp980261j

17. N. A. Pivovarova, Neftekhimiya, 59 (7), 727(2019), http://doi.org/10.1134/s002824211907013x

18. T.V. Shakiyeva, L.R. Sassykova, U.N. Dzhatkambayeva, N.K. Zhakirova, M. Prabhahar, S. Sendilvelan, M. Ganesan, N. Jaya Chitra and Rajeswari Hari, Materials Today: Proceedings, 45(7), 6028-6034(2021), http://doi.org/10.1016/j.matpr.2020.09.642

19. S. I. Kolesnikov, V.O. Zvyagin and I.M. Kolesnikov, Chemistry and Technology of Fuels and Oils, 2, 10(1999)

20. C.Boyadjian and L. Lefferts, European Journal of Inorganic Chemistry, 19, 1956(2018), http://doi.org/10.1002/ejic.201701280

21. M. Kiani Deh Kiani, S.Rostami, M.Eslami, T.Yusaf and S. Sendilvelan, Energy Conversion and Management, 165, 344(2018)

22. S. Fukase and F. Maruyama, Journal of The Japan Petroleum Institute, 37(6), 611(1994), http://doi.org/10.1627/jpi1958.37.611 
RASĀYAN J. Chem.

Vol. 14 | No. 4 |2216-2223| October- December | 2021

23. D. Baiseitov, M. Tulepov, L. Sassykova, Sh. Gabdrashova and Z.Mansurov, Bulgarian Chemical Communications, 49(3), 600(2017)

24. R. Kh. Salakhov, M. Seitzhanova, D.U. Bodykov, L.R. Sassykova, N.K. Zhakirova and T.M. Seilkhanov, Eurasian Chemico-Technological Journal, 22(4), 315(2020), http://doi.org/10.18321/ectj999

25. http://agpz.kz/proizvodstvo.html

26. D. Orlicki, U. Navarro, M. $\mathrm{Ni}$ and L. Langan, Chemical Industries, 173(2010), http://doi.org/10.1201/b10380-13

27. T. Cheung, Journal of Catalysis, 124(2), 511(1990), http://doi.org/10.1016/0021-9517(90)90197-r

28. T.V. Shakiyeva, L.R. Sassykova, U. N. Dzhatkambayeva, A.A. Khamlenko, N.K. Zhakirova, A.A. Batyrbayeva, R. N. Azhigulova, Sh. N. Kubekova, Zh. M. Zhaxibayeva, M. A. Kozhaisakova, L. A. Zhusupova, S. Sendilvelan and K. Bhaskar, Rasayan Journal of Chemistry, 14(2), 1065(2021), http://doi.org/10.31788/rjc.2021.1426152

29. B. Brunekreef and S.T. Holgate, Lancet, 9341(360), 1233(2002)

30. L. Sassykova, A. Nalibayeva, Y. Aubakirov, Z. Tashmukhambetova, U. Otzhan, N. Zhakirova and M. Faizullaeva, Oriental Journal of Chemistry, 33(4), 1941(2017), http://doi.org/10.13005/ojc/330440

31. Zh. Kh. Tashmukhambetova, N.K. Zhakirova, L.R. Sassykova, K.A. Kadirbekov, Y.A. Aubakirov and A.S. Zhumakanova, Oriental Journal of Chemistry, 33(6), 2803(2017), http://doi.org/10.13005/ojc/330613

32. S. Standl and O. Hinrichsen, Catalysts, 8(12), 626(2018), http://doi.org/10.3390/catal8120626

33. M.Ya. Bykhovskii, M.D. Shibanova, O.V. Udalova, D.P. Shashkin and V.N. Korchak, Oil and Gas Technologies, 1, 44(2013)

34. J. Sutrisnoa and A. Fuchsa, ECS Transactions, 28 (27), 1(2019), http://doi.org/10.1149/1.3496608

[RJC-6511/2021] 